\title{
Peer Review of "Telerehabilitation for People With Physical Disabilities and Movement Impairment: A Survey of United Kingdom Practitioners"
}

\author{
Anonymous \\ Related Articles: \\ Preprint: https://preprints.jmir.org/preprint/30516 \\ Authors' Response to Peer-Review Reports: https://med.jmirx.org/2022/1/e35845/ \\ Published Article: https://med.jmirx.org/2022/1/e30516/
}

(JMIRx Med 2022;3(1):e35848) doi: 10.2196/35848

\section{KEYWORDS}

telerehabilitation; physical disabilities; movement impairment; remote assessments; telehealth; rehabilitation; training; health care practitioners; physiotherapy; occupational therapy

This is a peer-review report submitted for the paper "Telerehabilitation for People With Physical Disabilities and Movement Impairment: A Survey of United Kingdom Practitioners.”

\section{Round 1 Review}

\section{General Comments}

This paper [1]: The manuscript has been well written and well organized; it needs some minor revisions.

\section{Minor Comments}

1. It is not clear how the authors have used a combination of "opportunity" and "snowball" sampling methods considering that these are two separate methods of purposeful sampling. Additionally, it is not clear how these methods have been used, so the sampling method and justification should be explained

\section{Conflicts of Interest}

None declared.

\section{Reference}

1. Buckingham SA, Anil K, Demain S, Gunn H, Jones RB, Kent B, et al. Telerehabilitation for people with physical disabilities and movement impairment: a survey of United Kingdom practitioners. JMIRx Med 2022;3(1):e30516 [FREE Full text] [doi: $\underline{10.2196 / 30516]}$ in more detail in the Methods section; although, it has been reported as a limitation of the study.

2. The first sentence of the Conclusions/Abstract is not based on the findings.

3. Delete this sentence from the Methods: "No statistical correction (such as weighting of items or use of propensity scores) was used; this was not felt to be appropriate as this was not a probabilistic sample."

4. Authors have reported their results for "pre covid-19 lock down," "during," and "post-covid national lock down"; this should be explained in the Methods section.

5. Providing a "Table" for reporting the results that have been reported in Figure 3 is more appropriate and readable.

6. Making some policy recommendations especially for reported obstacles of using telerehabilitation strengthens the Discussion. 


\section{JMIRx Med}

(C) Anonymous. Originally published in JMIRx Med (https://med.jmirx.org), 03.01.2022. This is an open-access article distributed under the terms of the Creative Commons Attribution License (https://creativecommons.org/licenses/by/4.0/), which permits unrestricted use, distribution, and reproduction in any medium, provided the original work, first published in JMIRx Med, is properly cited. The complete bibliographic information, a link to the original publication on https://med.jmirx.org/, as well as this copyright and license information must be included. 